\title{
Erythropoietin production in healthy volunteers subjected to controlled hypobaric hypoxia: further evidence against a role for adenosine
}

\author{
C. H. Gleiter,' 'T. Becker' \& J. Wenzel' \\ ${ }^{1}$ Abteilung Klinische Pharmakologie, Universität Göttingen, Göttingen, ${ }^{2}$ DLR Institut für Luft- und Raumfahrtmedizin, Köln, Germany
}

\begin{abstract}
Aims Objective of this study was to investigate whether adenosine modulates renal erythropoietin production.

Methods In the present study erythropoietin production was stimulated by hypobaric hypoxia by subjecting healthy volunteers to a simulated altitude of $4000 \mathrm{~m}$ in a low pressure chamber for $5.5 \mathrm{~h}$. During exposure to hypoxia the subjects received i.v. in a randomized, single-blind, cross-over fashion the non-specific adenosine antagonist theophylline, the adenosine reuptake inhibitor dipyridamole and placebo. Results Contrary to the working hypothesis, theophylline did not decrease and dipyridamole did not further boost erythropoietin concentrations.

Conclusions The results are in agreement with our earlier study using haemorrhage as a controlled physiological stimulus of erythropoietin production, and would question a major role for adenosine as a mediator of renal erythropoietin production.
\end{abstract}

Keywords: erythropoietin, theophylline, dipyridamole, hypobaric hypoxia, plasma renin activity, healthy volunteers

\section{Introduction}

There is some evidence from in vitro and animal experiments for the assumption that adenosine (ADO) might modulate renal erythropoietin (EPO) production [1]. According to this hypothesis, increasing renal ADO levels (e.g. under hypoxia [2]) would lead to an increased production of EPO and vice versa. Also, clinical data are available which may point towards such a role for ADO in humans. Bakris et al. [3] have shown that theophylline treatment in patients with post-transplant erythrocytosis (PTE) may reduce elevated EPO levels as well as haematocrit. However, this finding has not been unequivocally reproduced [4] and PTE is not considered a condition where the pharmacological control of EPO production can appropriately be assessed [5].

Our own animal experiments which assessed the ADO hypothesis systematically using selective adenosinergic compounds (not available for human use) in a model of functional hypoxia (by $\mathrm{CO}$ exposure) were unable to support this hypothesis [6]. Also, in a previous study we tried to assess this question in healthy volunteers who were subjected to a defined physiological stimulus of EPO production, namely haemorrhage. In this experiment the non-specific ADO antagonist theophylline did not inhibit the increase of EPO levels as predicted from the hypothesis [7]. The ADO reuptake inhibitor dipyridamole increases extracellular ADO levels. From theory and animal experiments it is expected to augment renal ADO effects [8]. In our previous experiment dipyridamole did not boost EPO levels [7] despite dipyridamole plasma levels which had been shown to inhibit ADO uptake in human platelets [9]. However, haemorrhage may not exert a signal to EPO

Correspondence: Dr C. H. Gleiter, Abteilung Klinische Pharmakologie, Universität Göttingen, Robert-Koch-Str. 40, D-37075 Göttingen, Germany. production that is fully comparable with hypoxia, e.g. as in some animal experiments [2]. Therefore, in a similar experimental design using theophylline and dipyridamole treatment, EPO production was stimulated by hypobaric hypoxia by subjecting healthy volunteers to a simulated altitude of $4000 \mathrm{~m}$ in a low pressure chamber.

\section{Methods}

Subjects

Seven healthy male non-smoking volunteers (mean age 25.1 years, range $20-31$ years, mean body weight $75.3 \mathrm{~kg}$, range $68-86 \mathrm{~kg}$ ) participated in the trial. The conditions for participation were identical with the earlier study [7]. The study was approved by the Ethics Committee of the University of Göttingen and the Ethics Committee of the Board of Physicians Nordrhein, Düsseldorf, Germany. Written, informed consent was obtained from each participant.

\section{Protocol}

The volunteers were subjected to hypoxia in a hypobaric chamber according to the protocol of Eckardt et al. [8]. In brief, the atmospheric pressure was reduced to 460 Torr (4000 $\mathrm{m}$ above sea level) with an interruption for $15 \mathrm{~min}$ at 600 Torr during the ascent $(2000 \mathrm{~m}$ above sea level). The subjects remained in the chamber for a total of $5.5 \mathrm{~h}$. Thirty min before the subjects were exposed to hypoxia i.v. drug medication was started and administered for $6 \mathrm{~h}$ by an infusion pump (Perfusor ${ }^{\circledR}$, Braun Melsungen AG, Germany) until the end of the stay in the chamber. The subjects received in a randomized, cross-over, single-blind design placebo $\left(0.9 \mathrm{~g} \mathrm{dl}^{-1} \mathrm{NaCl}\right)$, or theophylline $\left(5 \mathrm{mg} \mathrm{kg}^{-1}\right.$ 


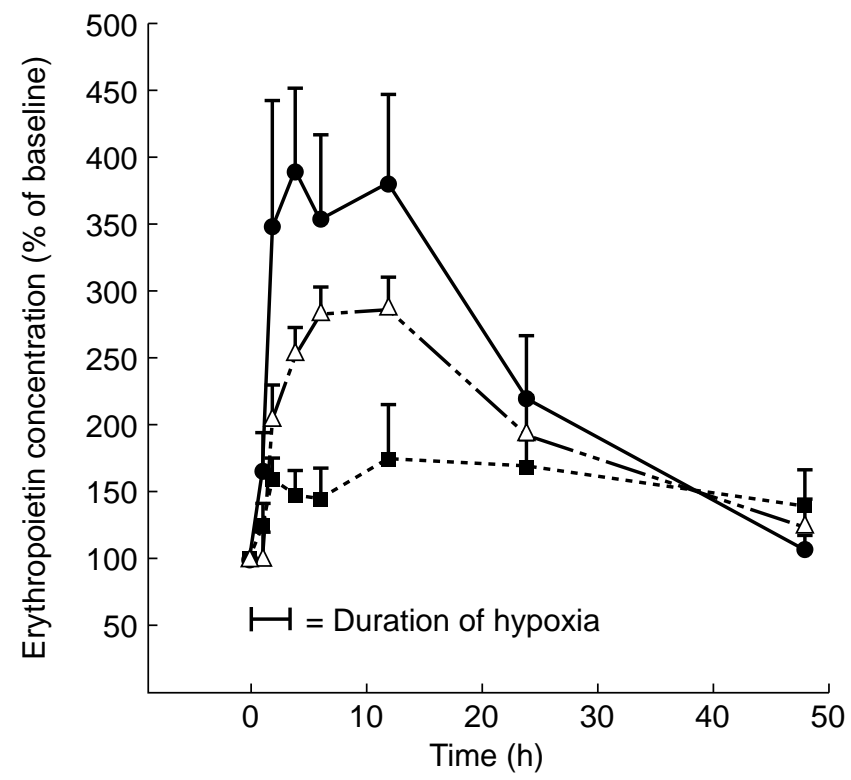

Figure 1 Time course of erythropoietin serum concentrations expressed as percent of baseline values (mean \pm s.e.mean). The period of exposure towards hypobaric hypoxia is indicated. theophylline; $\mathbf{\square}$ dipyridamole; $\triangle$ placebo.

loading dose over $20 \mathrm{~min}$, followed by a continuous infusion of $0.5 \mathrm{mg} \mathrm{kg}^{-1} \mathrm{~h}^{-1}$ over the remaining $340 \mathrm{~min}$; Euphyllin $\left.200^{\circledR}\right)$, or dipyridamole $\left(0.21 \mathrm{mg} \mathrm{kg}^{-1} \mathrm{~h}^{-1}\right.$; Persantin $\left.{ }^{\circledR}\right)$. The treatments were separated by wash out periods of at least 2 weeks. In the chamber the subjects remained in the sitting position. Arterial haemoglobin oxygen saturation $\left(\mathrm{SaO}_{2}\right)$ was measured by a pulse oximeter with a fingerclip sensor. Haemoglobin and haematocrit were measured before hypoxia and 2, 6, 24, and $48 \mathrm{~h}$ thereafter. Blood pressure and heart rate were recorded before, and 2, 4, 6, 8 and $12 \mathrm{~h}$ after the start of hypoxia. Drug concentrations were measured before and after $4 \mathrm{~h}$ of the respective drug infusions. Blood samples for EPO concentrations were taken as shown in Figure 1. Plasma renin activity (PRA) was measured before hypoxia as well as 2, 4, 6, 8, and $12 \mathrm{~h}$ thereafter.

\section{Analytical methods and statistics}

Haemoglobin, haematocrit, dipyridamole and theophylline, PRA and EPO were analysed as described previously [7]. The area under the concentration-time curve (AUC) was calculated by the linear trapezoidal rule. Values are expressed as mean \pm s.e.mean and were analyzed by repeated measures ANOVA followed in the case of a significant finding by $t$-tests with Bonferroni-Holm correction.

\section{Results}

Oxygen saturation fell in all groups from 100\% to about $85 \%$ during hypoxia. Within the $48 \mathrm{~h}$ observation period after the start of hypoxia, haemoglobin and haematocrit values were very similar in all groups and unaltered by treatment (data not shown). Four hours after the start of the i.v. drug infusion the mean plasma concentration of theophylline was $13.7 \pm 0.4 \mathrm{mg}^{-1}$ and that of dipyridamole $1.5 \pm 0.2 \mu \mathrm{g} \mathrm{ml}^{-1}$. In all treatment groups mean systolic blood pressure fell during the first $2 \mathrm{~h}$ of hypoxia $(P>0.05)$, mean diastolic blood pressure was about $5 \mathrm{mmHg}$ lower during infusion of theophylline during the first $2 \mathrm{~h}$ of hypoxia $(P<0.05)$. Otherwise there were no major changes of blood pressure during the entire experiment (data not shown). Heart rate increased significantly $(P<0.05)$ during hypoxia in all three treatment groups by about 15 beats $\min ^{-1}$ (data not shown).

$\operatorname{AUC}_{\text {PRA theophylline }}(0,12 \mathrm{~h})\left(68.7 \pm 8.7\left(\mathrm{ng} \mathrm{ml}^{-1} \mathrm{~h}^{-1}\right)\right.$. h)] was statistically significantly larger than $A U C_{P R A}$ placebo $(0,12 \mathrm{~h})\left(26.0 \pm 4.7\left(\mathrm{ng} \mathrm{ml}^{-1} \mathrm{~h}^{-1}\right) \cdot \mathrm{h}\right)$; difference of means $42.7\left(\mathrm{ng} \mathrm{ml}^{-1} \mathrm{~h}^{-1}\right) \cdot \mathrm{h}, 95 \%$ CI 22.4 to $63\left(\mathrm{ng} \mathrm{ml}^{-1}\right.$ $\left.\left.\left.\mathrm{h}^{-1}\right) \cdot \mathrm{h}\right) ; \mathrm{P}<0.001\right)$. AUC $\mathrm{PRA}_{\text {dipyridamole }}(0,12 \mathrm{~h})$ was not different from AUC ${ }_{\text {PRA placebo }}(0,12 \mathrm{~h})\left(24.5 \pm 3.8\left(\mathrm{ng} \mathrm{ml}^{-1}\right.\right.$ $\left.\left.\mathrm{h}^{-1}\right) \cdot \mathrm{h}\right)$ ). Baseline EPO levels were $3.5 \pm 0.5$ (theophylline), $5.4 \pm 0.6$ (dipyridamole) and $4.4 \pm 0.6 \mathrm{mu} \mathrm{ml}^{-1}$ (placebo). The time course of EPO concentrations is given in Figure 1. There were no statistically significant differences between $\mathrm{AUC}_{\mathrm{EPO}}(0,48 \mathrm{~h})[\mathrm{h} \%$ of baseline] of theophyllinetreated $(11653 \pm 1885)$ or dipyridamole-treated subjects $(7628 \pm 641)$ in comparison with placebo $(9711 \pm 957)$.

\section{Discussion}

The results concerning the course of blood pressure and heart rate from the placebo group were in accordance with earlier observations using the same hypobaric protocol [10]; the verum treatments did not alter the obviously hypoxiarelated changes. Theophylline and dipyridamole concentrations were comparable with those achieved in our first study [7]. Thus, theophylline plasma concentrations were in the range for the treatment of asthma and effective blockade of ADO receptors is assumed [11]. Plasma concentrations of this order of magnitude have been achieved in patients with effective control of PTE [3]. Dipyridamole plasma concentrations were of the order of magnitude where an inhibition of ADO reuptake was demonstrated in platelets of normal subjects after oral administration [9].

The increase of EPO during placebo treatment was similar to that in the study by Eckardt et al. [8]. The onset of EPO production was more rapid than after phlebotomy [7]. However, in agreement with this earlier study, there was no inhibition of EPO production by theophylline and no further boost by dipyridamole. In fact, we found-as in our earlier study - an increase of EPO production under theophylline; this increase was not statistically significant. Also, PRA values were of the same order of magnitude as in our previous study [7], confirming that hypoxia did not change the effect of the treatments on PRA. A clear increase during theophylline infusion was demonstrated. PRA is a variable that is modulated by sympathoadrenergic signals [12]. As outlined earlier, theophylline may block presynaptic adenosine receptors thereby increasing sympathetic signal transduction. This led us to conclude that the further increase of EPO levels under theophylline may be caused by an increased sympathetic tone. Another trial has addressed this hypothesis, and a clear stimulating effect was shown for the $\beta_{2}$-adrenoceptor agonist fenoterol [13].Taken together, these data are in agreement with those from our experiment using phlebotomy and do not support a role for adenosine in the control of erythropoietin production. 
The authors wish to thank Dr M. Heer, DLR Institut für Luft- und Raumfahrtmedizin, for her many helpful contributions during this trial.

\section{References}

1 Fisher J. Regulation of erythropoietin production. In Handbook of Renal Physiology, Vol. II, ed Windhager EE, New York: Oxford University Press, 1992; 2407-2438.

2 Osswald H, Schmitz HJ, Kemper R. Tissue content of adenosine, inosine and hypoxanthine in the rat kidney after ischemia and postischemic recirculation. Pflïgers Arch 1977; 371: 45-49.

3 Bakris GL, Sauter ER, Hussey JL, et al. Effects of theophylline on erythropoietin production in normal subjects and in patients with erythrocytosis after renal transplantation. N Engl J Med 1990; 323: 86-90.

4 Ilan Y, Dranitzki-Elhallei M, Rubinger D, et al. Erythrocytosis after renal transplantation. Transplantation 1994; 57: 661-664.

5 Gleiter CH. Postransplant erythrocytosis: A model for the investigation of the pharmacological control of renal erythropoietin production? Int J Clin Pharmacol 1996; 11: 489-492.

6 Gleiter CH, Brause M, Delabar U, Eckardt KU. Evidence against a major role of adenosine in oxygen-dependent regulation of erythropoietin in rats. Kidney Int 1997; (in press).

7 Gleiter CH, Freudenthaler S, Delabar U, et al. Erythropoietin production in healthy volunteers subjected to controlled haemorhage: evidence against a major role for adenosine. $\mathrm{Br}$ J Clin Pharmacol 1996; 42: 729-735.

8 Osswald H, Gleiter C, Mühlbauer B. Therapeutic use of theophylline to antagonize renal effects of adenosine. Clin Nephrol 1995; 43: (Suppl 1): S33-S37.

9 Summers A, Subbaro K, Rucinski B, et al. The effect of dipyridamole on adenosine uptake by platelets ex vivo. Thromb Res 1977; 11: 611-618.

10 Eckardt KU, Bouteiller U, Kurtz A, et al. Rate of erythropoietin formation in humans in response to acute hypobaric hypoxia. J Appl Physiol 1989; 66: 1785-1788.

11 Serafin W. Drugs used in the treatment of asthma. In Goodman and Gilman's The Pharmacological Basis of Therapeutics, eds Hardman JG, et al. New York: McGraw-Hill, 1996; 659-682.

12 Jackson EK, Garrison JC. Renin and angiotensin. In Goodman and Gilman's The Pharmacological Basis of Therapeutics, eds Hardman JG, et al. New York: McGraw-Hill, 1996; 733-758.

13 Gleiter $\mathrm{CH}$, Becker T, Schreeb KH, et al. Fenoterol but not dobutamine increases erythropoietin production in humans. Clin Pharmacol Ther 1997; (in press).

(Received 3 January 1997, accepted 26 March 1997) 